\title{
C2 Pars/Pedicle Screws in Management of Craniocervical and Upper Cervical Instability
}

\author{
Mohammed Ahmed Eshra \\ Department of Neurosurgery, Faculty of Medicine, Alexandria University, Alexandria, Egypt
}

\begin{abstract}
Study Design: A retrospective study.
Purpose: To evaluate the efficacy and the safety of craniocervical and upper cervical stabilization by using C2 pars/pedicle screw fixations.

Overview of Literature: The management of craniocervical and upper cervical instability has progressed over the past two decades due to good achievements in the instrumentation and the increased awareness on spinal anatomy and biomechanics. However, there is insufficient studies or solid conclusions on this topic, thus, we tried to investigate and present our findings.

Methods: Twenty-two patients were operated upon and were followed up from March 2008 to October 2010. One patient had craniocervical instability (post-surgical), 15 patients had atlantoaxial instability of different etiologies (trauma, tumors, inflammatory and degenerative) and 6 patients had hangman fractures. Patients' ages ranged from 18 to 52 years old. with 5 female patients and 17 male patients.

Results: Radiological follow ups performed immediately post-operation showed good screw positioning and complete reductions in nearly all the cases. All patients were followed up for more than one year. Sound fusions were observed among all patients.

Conclusions: The use of pars/pedicle screws is a very effective, sound, safe and easy surgical modality for treating craniocervical, atlantoaxial and upper cervical instabilities. Increasing studies for the biomechanics of this important region and longer periods of follow-ups are necessary to document the usefulness of this modality when treating such patients.
\end{abstract}

Keywords: Craniocervical; Cervical spine; C2 pars screws, C2 pedicle

\section{Introduction}

C2 pars/pedicle screws have been a good and sound way of fixation during posterior upper cervical spine surgery $[1,2]$. The use of the pedicle and pars of $\mathrm{C} 2$ as a part of complex upper cervical spine, has allowed spine surgeons to use these structures for fixation of the anterior and posterior segments of the $\mathrm{C} 2$ vertebra, as in cases of Hangman's fractures [3-5].

Nowadays craniocervical instability is treated with an occipital plate with a C1 lateral mass and C2 pars/pedicle screws using polyaxial screw-rod fixation, atlantoaxial instability with a $\mathrm{C} 1$ lateral mass and $\mathrm{C} 2$ pedicle screws, and Hangman's fracture is treated by C2 pars screws with or without C3 lateral mass screws and rods. Atlantoaxial stabilization with a C1 lateral mass and C2 pars/ pedicle screws has other advantages over the transarticular screws such as the ease of performing the procedure and the possibility of intraoperative reduction. However, the advantages are without risk of vertebral artery (VA)

Received Apr 21, 2013; Revised Jun 11, 2013; Accepted Jul 8, 2013

Corresponding author: Mohammed Ahmed Eshra

Department of Neurosurgery, Faculty of Medicine, Alexandria University, Alexandria, Egypt

Tel: +20-1001529424, Fax: +20-035564285, E-mail: eshrawyalatool@yahoo.com 
injury [6,7]. The management of craniocervical and upper cervical instability has progressed over the past two decades due to good achievements in instrumentation and increased awareness about spinal anatomy and biomechanics. Posterior fixation of the cervical spine is a popular surgical procedure which is used in a variety of spinal disorders, such as cervical spondylosis, postsurgical deformity or instability, tumor, and trauma [8].

\section{Materials and Methods}

Twenty-two patients were operated upon and were followed up from March 2008 to October 2010. One patient had craniocervical instability (postsurgical), 15 patients had atlantoaxial instability of different etiologies (trauma, tumors, inflammatory, and degenerative) and six patients had Hangman's fracture. Patients' ages ranged from 18 to 52 years. Five female patients and 17 male patients. The patient who had craniocervical instability was operated upon by occipital plate fixation, $\mathrm{C} 1$ lateral mass screws and C2 pars/pedicle screws. Patients who had atlantoaxial instability were operated upon by $\mathrm{C} 1$ lateral mass screws and C2 pars/pedicle screws. Four patients who had Hangman's fracture were operated upon by C3 lateral mass screws and C2 pars/pedicle screws. Two patients who had Hangman's fracture were operated upon by C2 pars/pedicle screws only.

\section{Surgical technique}

Under general anesthesia using awake intubation and fiber optics guidance, the patient was put in the prone position with the neck neutralized, the head was fixed in a Mayfield and the arms were adducted to the body. A posterior midline skin incision was made from the suboccipital region to the $\mathrm{C} 4$ spinous process.

The lateral mass of $\mathrm{C} 1$, which lies below the lateral half of the $\mathrm{C} 1$ posterior arch, was palpated using a microdissector to detect the medial and lateral limits of this mass. The entry site for the $\mathrm{C} 1$ lateral mass was the midpoint between the medial and lateral edges. Under C-arm guidance, a high speed drill was used to penetrate the cortex at 15 degrees of medial inclination and direction towards the anterior tubercle of $\mathrm{C} 1$. The track was palpated using a micro sensor then tapped, and a polyaxial, 28 to $30 \mathrm{~mm}$ length, $3 \mathrm{~mm}, 5 \mathrm{~mm}$ diameter screw was inserted.

The C2 pars is located between the superior and in- ferior articular surfaces and its anterior continuation is the pedicle which is short, and is attached anteriorly and originates from the $\mathrm{C} 2$ body. The entry point for the $\mathrm{C} 2$ pars/pedicle screw is located $5 \mathrm{~mm}$ above and lateral to the inferomedial angle of the $\mathrm{C} 2-3$ facet joint. With a 10 to 15 degree medial inclination and 45 degree up-pointing toward the anterior $\mathrm{C} 1$ tubercle, the drilling was followed by tapping. We inserted a $16 \mathrm{~mm}$ polyaxial screw for the pars screw and a 30 to $32 \mathrm{~mm}$ for the pars/pedicle screw. In cases of Hangman's fracture, if there was much displacement or angulation (type 2 or 3 Hangman's fracture), this deformity was completely or partially reduced by skull/neck traction before screw insertion. Rods were refashioned to comply with the normal lordotic curve and then were applied over the screws. We decorticated the exposed surfaces of the $\mathrm{C} 1$ lamina and $\mathrm{C} 2$ lateral masses to accommodate the fragmented bony grafts. We closed in layers and applied suction drainage. Postoperatively, a hard Philadelphia neck collar was applied and maintained for 3 months. All patients were followed up clinically and radiologically for at least one year.

\section{Results}

No major intraoperative complications were encountered. A few postoperative complications in the form of superficial wound infection in 4 cases were treated conservatively. Pre- and postoperative data collection and analysis of the outcomes were completed based on the Oswestry Disability Index (ODI) and American Spine Injury Association (ASIA) Impairment Scale.

\section{Oswestry Disability Index}

The ODI was scored on a 0-100 scale using the Oswestry Low Back Pain Disability Questionnaire of ten items (personal care, lifting, walking, sitting, standing, sleeping, sex life, social life, travelling, and need for medications). On this scale, $0-20$ equates to minimal disability, $21-40$ moderate disability, 41-60 severe disability, 61-80 crippled, and 81-100 bed-bound or exaggerating.

The outcome was categorized as in the following: 1) poor outcome (ODI, 81-100): patients who experienced the same preoperative symptoms or worsening of the symptoms after surgery, with significant restriction of their daily living activities; 2) fair outcome (ODI, 61-80): pain had improved compared with the preoperative sta- 
tus but still requiring strong analgesics; evidence of mild improvement in sensory and motor symptoms but the patient still had some difficulty with daily living activities; 3) good (ODI, 41-60): Patients had moderate improvement in the back pain and sciatica, and only mild analgesics were required and only mild numbness and paresthesia experienced, with a noticeable improvement in the weakness. Little constraint in daily activities; 4 ) very good (ODI, 21-40): moderate improvement in the back pain and sciatica, no analgesics were required at any time and less numbness and paresthesia experienced, with no weakness. No constraint in daily activities anymore; 5) excellent (ODI, 0-20): No more pain or neurological deficits. Normal daily life activities and patient's satisfaction was more than $80 \%$.

\section{ASIA Impairment Scale}

A) Complete: no motor or sensory function is preserved in the sacral segments S4-S5. B) Incomplete: Sensory but not motor function preserved below the neurologic level and includes the sacral segments S4-S5. C) Motor function is preserved below the neurologic level, and more

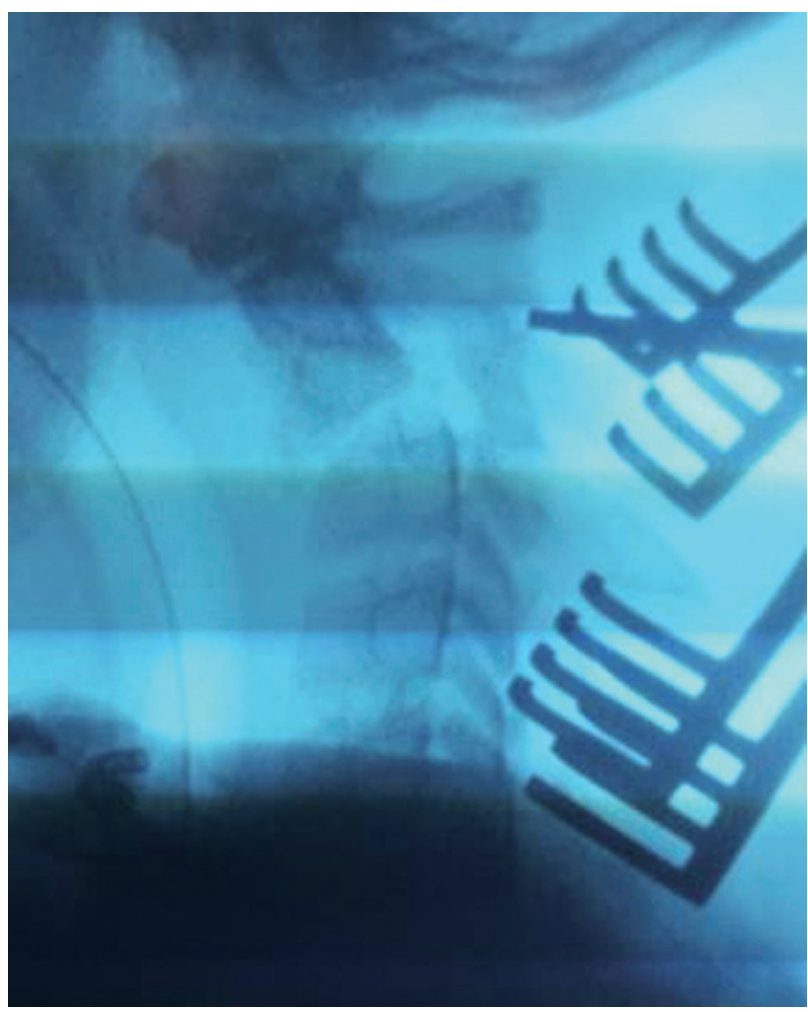

Fig. 1. Intraoperative C-arm image showing an angulateddislocated C2 in this case of Hangman's fracture. than half of the key muscles below the neurologic level have a muscle grade less than 3. D) Incomplete: motor function is preserved below the neurologic level, and at least half of the key muscles below the neurologic level have a muscle grade of 3 or more. E) Normal: motor and sensory functions are normal.

There was no deterioration in the patients' clinical condition in any of the cases, whereas clinical improvement started in $80 \%$ of the cases. Radiological follow-up done in the immediate postoperative period confirmed good position of the screws. The criteria or definitions of "good screw position" entails the following [9]: 1) The $\mathrm{C} 2$ pedicle should be palpated using a fine dissector after removal of the soft tissues with no serrations palpated in the spinal canal. 2) No evidence of VA injury as intraoperative hemorrhage or postoperative neurological deterioration. 3) Intraoperative and postoperative radiological assessment showing complete reduction and screws observed passing through the $\mathrm{C} 2$ pedicle to the $\mathrm{C} 2$ body without breaching the cortex of the pedicle.

All patients were followed up for more than one year. Sound fusions were observed in all patients and confirmed by postoperative flexion-extension lateral radio-

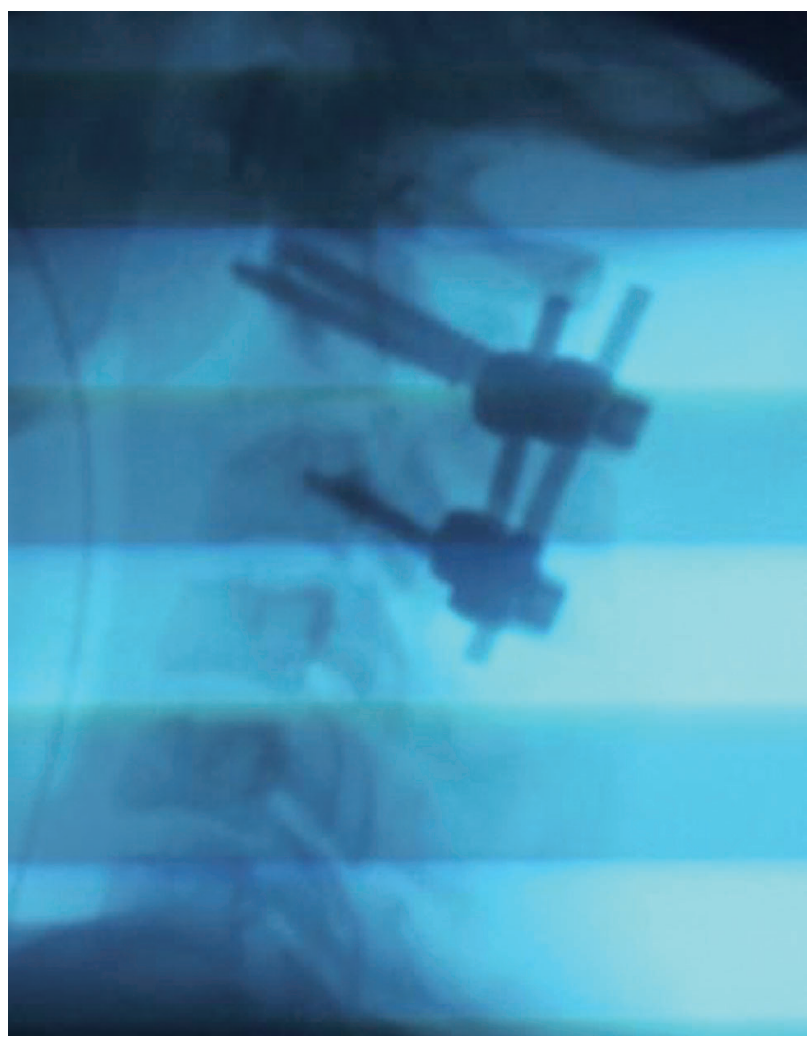

Fig. 2. Nearly complete reduction with C2 pars screws and C3 lateral mass. 
graphs (Figs. 1-4).

\section{Discussion}

Mixter and Osgood [10] have the first trials to fix $\mathrm{C} 1$ and C2 through the posterior approach using silk wires in 1910.

Goel and Laheri [11] and Gupta and Goel [12] were the first surgeons to try to fuse $\mathrm{C} 1$ and $\mathrm{C} 2$ from the posterior approach by inserting $\mathrm{C} 1$ lateral mass screws and $\mathrm{C} 2$ pars/pedicle screws. This procedure is done nowadays by the vast majority of spine surgeons. The many advantages of this technique include the allowance of 0.6 degrees more motion than with a $\mathrm{C} 1-2$ transarticular screw, anomalies in the VA course have no effect, and insertion of the $\mathrm{C} 2$ pars/pedicle screw gives a better bony grip that is more powerful than the $\mathrm{C} 2$ lateral mass $[11,12]$.

In atlantoaxial subluxation, many surgeons use the posterior wiring technique, but it does not have sufficient rigidity, needs postoperative halo immobilization and needs an intact posterior arch of C1 and C2 [13].

Hangman's fracture can be treated through the ante-

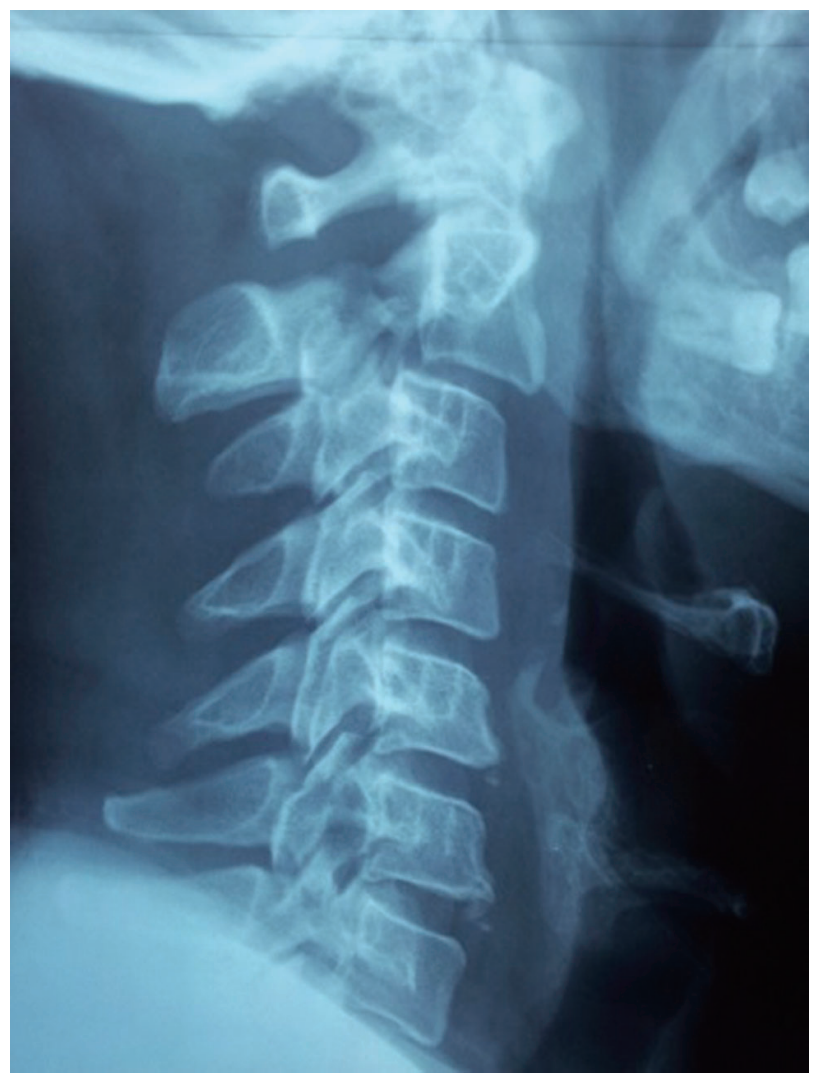

Fig. 3. Dislocated C2 in the case of a Hangman's fracture. rior, transoral or extra oral approach, with violation of the $\mathrm{C} 2-3$ disc, and insertion of a bone graft and fixation of the 2 bodies using a cervical plate and screws. This approach sometimes is very difficult, especially in obese patients or patients with a short neck. In contrast, the posterior approach using pars/pedicle screws is easy and can be done in most of the patients $[3,13]$. In cases of Hangman's fracture treated by pars/pedicle screws only, the motion at the $\mathrm{C} 2-3$ segment is preserved and normal cervical lordosis is maintained [5,14]. If Hangman's fracture is associated with traumatic $\mathrm{C} 2-3$ disc herniation, some authors recommend trying the anterior approach [15].

In cases of high-riding VA or medially positioned VA, $16 \mathrm{~mm}$ pars screws are used (not reaching the pedicle) or laminar screws are employed [16].

The use of recent surgical techniques incorporating computer-assisted navigation systems increases the accuracy of $\mathrm{C} 2$ pedicle screw fixation. When such navigation is used, greater safety and accuracy may be achieved.

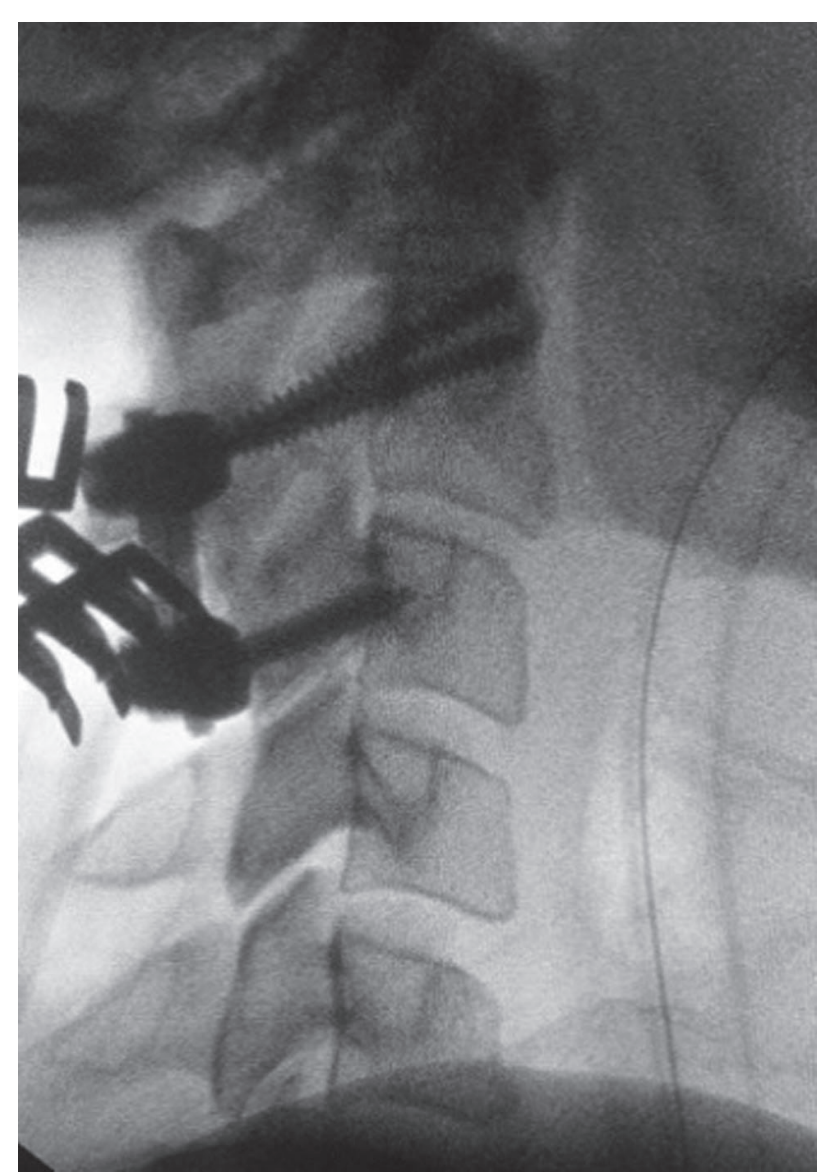

Fig. 4. Complete reduction with C2 parsscrews and C3 lateral mass screws. 
Finally, we spent much time and effort trying to produce good results and to clarify the efficacy of this new technique, with limited facilities, but the study lacked a large series, and longer periods of follow up are required.

\section{Conclusions}

The use of pars/pedicle screws is a very effective, sound, safe and easy to use surgical modality for treating craniocervical, atlantoaxial, and upper cervical instability. More studies on the biomechanics of this important region and longer periods of follow up are needed to document the usefulness of this modality of treating such patients.

\section{Conflict of Interest}

No potential conflict of interest relevant to this article was reported.

\section{References}

1. Xiao ZM, Zhan XL, Gong de F, Chen QF, Luo GB, Jiang $\mathrm{H}$. C2 pedicle screw and plate combined with $\mathrm{C} 1$ titanium cable fixation for the treatment of atlantoaxial instability not suitable for placement of $\mathrm{C} 1$ screw. J Spinal Disord Tech 2008;21:514-7.

2. Xie N, Ni B, Chen DY, Ye XJ, Xiao JR, Yuan W. Combined anterior $\mathrm{C} 2,3$ reduction and fusion with posterior compressive $\mathrm{C} 2$ pedicle screw fixation for the treatment of unstable Hangman's fractures: 16 cases review. Zhonghua Wai Ke Za Zhi 2008;46:267-9.

3. Hakalo J, Wronski J. Operative treatment of hangman's fractures of C2. Posterior direct pars screw repair or anterior plate-cage stabilization? Neurol Neurochir Pol 2008;42:28-36.

4. Rajasekaran S, Vidyadhara S, Shetty AP. Iso-C3D fluoroscopy-based navigation in direct pedicle screw fixation of Hangman fracture: a case report. J Spinal Disord Tech 2007;20:616-9.

5. Taller S, Suchomel P, Lukas R, Beran J. CT-guided internal fixation of a hangman's fracture. Eur Spine J 2000;9:393-7.

6. Resnick DK, Lapsiwala S, Trost GR. Anatomic suitability of the C1-C2 complex for pedicle screw fixation. Spine (Phila Pa 1976) 2002;27:1494-8.

7. Yoshida M, Neo M, Fujibayashi S, Nakamura T. Comparison of the anatomical risk for vertebral artery injury associated with the $\mathrm{C} 2$-pedicle screw and atlantoaxial transarticular screw. Spine (Phila Pa 1976) 2006;31:E513-7.

8. Deen HG, Birch BD, Wharen RE, Reimer R. Lateral mass screw-rod fixation of the cervical spine: a prospective clinical series with 1-year follow-up. Spine J 2003;3:489-95.

9. Lee $\mathrm{KH}$, Kang DH, Lee CH, Hwang SH, Park IS, Jung JM. Inferolateral entry point for c2 pedicle screw fixation in high cervical lesions. J Korean Neurosurg Soc 2011;50:341-7.

10. Mixter SJ, Osgood RB. IV. Traumatic lesions of the atlas and axis. Ann Surg 1910;51:193-207.

11. Goel A, Laheri V. Plate and screw fixation for atlanto-axial subluxation. Acta Neurochir (Wien) 1994;129:47-53.

12. Gupta S, Goel A. Quantitative anatomy of the lateral masses of the atlas and axis vertebrae. Neurol India 2000;48:120-5.

13. Wilson AJ, Marshall RW, Ewart M. Transoral fusion with internal fixation in a displaced hangman's fracture. Spine (Phila Pa 1976) 1999;24:295-8.

14. Suchomel P, Hradil J, Barsa P, et al. Surgical treatment of fracture of the ring of axis-"hangman's fracture". Acta Chir Orthop Traumatol Cech 2006;73:321-8.

15. Verheggen R, Jansen J. Hangman's fracture: arguments in favor of surgical therapy for type II and III according to Edwards and Levine. Surg Neurol 1998;49:253-61.

16. Kim SY, Jang JS, Lee SH. Posterior atlantoaxial fixation with a combination of pedicle screws and a laminar screw in the axis for a unilateral high-riding vertebral artery. J Korean Neurosurg Soc 2007;41:141-4. 